\title{
Psychometric properties of fatigue severity scale in Chinese systemic lupus erythematosus patients
}

\author{
Chenchen Feng ${ }^{\dagger}$, Qian He ${ }^{\dagger}$, Yan Wu, Xiaokun Hu, Juan Wu, Xiaoli He and Shuzhen Zhao ${ }^{*}$ (D)
}

\begin{abstract}
Background: Fatigue is the most common symptom in Systemic Lupus Erythematosus (SLE) patients. Many fatigue instruments have been used in SLE, with Fatigue Severity Scale (FSS) mostly adopted. However, fatigue instruments haven't been tested in the Chinese SLE population. The aim of our study was to test the psychometric properties of FSS in Chinese SLE patients.
\end{abstract}

Methods: A cross-sectional study was conducted. 201 patients diagnosed with SLE were enrolled in the study with convenience sampling. Fatigue score, depression score and vitality subscale score of SF-36 were collected. Floor and ceiling effects were tested. Factor analysis was conducted. Reliability and validity of FSS were also tested.

Results: Floor (4.50\%) and ceiling (4.00\%) effects were minimal. One factor was extracted, explaining $61.80 \%$ of total variance. When item 1 and item 2 were deleted, one factor explained $69.54 \%$ of variance, and Cronbach's Alpha increased from 0.92 to 0.93 . Intraclass correlation coefficient (ICC) was 0.94. Fatigue correlated with both depression $(r=0.52, P<0.01)$ and vitality $(r=-0.55, P<0.01)$, indicating acceptable construct validity for original FSS. When item 1 and 2 were removed, the correlation coefficient between 7-item FSS and vitality increased $(r=-0.58, P<0$. $01)$, while correlation coefficient between 7 -item FSS and depression remained the same $(r=0.52, P<0.01)$. Knowngroups validity was verified by that patients with depression showed higher fatigue score both for 9 -item $(Z=-5.56$, $P<0.001)$ and 7 -item FSS $(Z=-5.70, P<0.001)$.

Conclusions: 9 -item FSS is a reliable instrument and can be used to assess fatigue problem in Chinese SLE patients, and 7-item FSS also demonstrated good psychometric properties in the same participants.

Keywords: Fatigue, Psychometric properties, Scale, Systemic lupus erythematosus

\section{Background}

Systemic lupus erythematosus (SLE) is a multisystem, autoimmune, inflammatory disorder presenting with symptoms from various organs, including joint, skin, kidney, brain, cardiovascular, lung, etc. [1]. In western countries and the United States, SLE prevalence was 4 to 250/ 100,000 in adult. In China, its prevalence was 97.5 to $100 /$ 100,000 [2-5]. The peak SLE incidence occurs at age 2029 years, followed by $30-39$ years old for females, but in 70-74 years old for males [3], and the female-to-male ratio was about 10:1 in China [6-8]. The most common

\footnotetext{
* Correspondence: ssszszzsz@126.com

Chenchen Feng and Qian He should be considered as co-first authors

Outpatient Department, West China Hospital of Sichuan University, No. 37,

Guoxue Lane, Chengdu 610041, Sichuan Province, People's Republic of China
}

symptom of SLE is fatigue, with about 51\% 90\% of SLE patients experiencing fatigue problem [9]. Fatigue can affect the daily lives of SLE patients [10,11], and is also related to sleep disorders [12], pain, depression, and quality of life [13]. Fatigue is a subjective phenomenon without clinically validated definition [14], and it's hard for patients with fatigue problem to participate in a long time investigation, so a reliable and simple instrument to measure fatigue problem of SLE is important, which would be conducive to interventions and outcomes monitoring.

Many fatigue instruments have been used in SLE patients. A study conducted a systematic review of the fatigue instruments used in SLE patients. 15 instruments were found, including Visual Analogue Scale [15], Fatigue Severity Scale (FSS) [16], Chalder Fatigue Scale [17], 
Multidimensional Fatigue Inventory (20 items) [18], etc. The study found that FSS was most widely used and recommended the use of FSS to measure fatigue for SLE patients. First developed and tested by Krupp in SLE and multiple sclerosis patients [16], FSS was used to measure the impact of fatigue on functions [9]. It is a unidimensional fatigue scale with 9 items. FSS has also been used in diseases other than SLE, such as cancer [19], chronic hepatitis C [20], central neural system disease [21], chronic neck pain [22], major depressive disorder [23], stroke [24, 25], as well as general population [26]. Though widely used in other countries, past properties test of FSS in SLE enrolled relatively small number of participants [27-29], and the FSS hasn't been tested in Chinese SLE patients. The properties of a scale are related to specific patient group and cultural factors, so the aim of our study was to test the psychometric properties of FSS in Chinese SLE.

\section{Patients and methods Study design}

A cross-sectional study was conducted in a rheumatology outpatient in one general hospital in Chengdu, China.

\section{Patients}

Between May 2017 and July 2017, 201 patients were enrolled in the study by convenience sampling from the Rheumatic Outpatient Clinic of West China Hospital of Sichuan University. Inclusion criteria: (1) 18 to 75 years old, (2) diagnosed with American College of Rheumatology revised criteria for the classification of SLE [30], (3) having no communication problems with interviewers, (4) informed consent. Exclusion criteria: (1) with comorbid fatigue-related conditions such as cancer, obesity (BMI $\geq$ $28 \mathrm{Kg} / \mathrm{m}^{2}$ ), pregnant, taking medications that affect sleep, central neural system disease, rheumatoid arthritis, etc.

\section{Measurements \\ Demographic and clinical variables}

Demographic and clinical variables were collected from each patient, including age, gender, level of education, residence, current work status, average monthly household income, medical insurance, whether having caregiver, disease duration, disease activity assessed with Systemic Lupus Erythematosus Disease Activity Index (SLEDAI), daily glucocorticoids dose, and depression.

\section{FSS}

FSS was used to test patients' fatigue severity. This instrument contains 9 items, and patients choose score from 1 (strongly disagree) to 7 (strongly agree) to indicate their agreement level to each item. The total score is the mean of 9 items' scores, with higher score indicating higher degree of fatigue. Score 4 or higher means having fatigue [31].

\section{Self-rating depression scale (SDS)}

SDS was used to assess the depression of patients. It has 20 items, and all items are scored from 1 to 4 to specify the occurrence frequency. Score over 70 means severe depression, score between 60 and 69 indicating moderate to marked depressive symptoms, score between 50 and 59 meaning minimal to mild depression, and score less than 50 indicates no depression [32].

\section{Sf- 36}

SF- 36 was used to measure patient's quality of life. It has 8 subscales: Physical Functioning (10 items), Role-Physical (4 items), Bodily Pain (2 items), General Health (5 items), Vitality (4 items), Social Functioning (2 items), Role-Emotional (3 items), and Mental Health (5 items). Item scores were coded, summed, and transformed. Total score ranges from 0 to 100, with higher score indicating better health status [32]. The Vitality subscale was used to test the concurrent validity of FSS.

\section{Data collection procedures}

The study was approved by the Ethics Committees of West China Hospital of Sichuan University (2017/137). When patients visited the rheumatology outpatient clinic, rheumatologists first diagnosed SLE patients with American College of Rheumatology revised criteria. Then, rheumatologists excluded patients with comorbid fatigue-related conditions. The doctors would introduce the study to SLE patients first. When patients finished their visits, two researchers informed patients who met other inclusion criteria of the aim and procedures of the study. After giving their informed consents, patients were instructed to fill in the questionnaires. One week after their visits, two researchers made phone calls to the same participants and investigated their fatigue scores again.

\section{Statistical analysis}

SPSS software (SPSS Inc., Chicago, IL, USA; version 17.0) was used. Floor and ceiling effects were applied to test the acceptability of the scale. Exploratory factor analysis was used to explore the dimensional structure of the FSS. Principal factor was used to extract factors, and quartimax rotation was applied. Eigen value above 1.00 and the scree plot were used to confirm the factor number. The Cronbach alpha was used to indicate FSS's internal consistency. The test-retest reliability was determined by the intraclass correlation coefficient (ICC), which was calculated by SLE patients' FSS scores collected at two different times. To test the concurrent validity, spearman correlation was adopted to explore the correlation between FSS score and depression score, as well as the correlation between FSS score and Vitality score. To test known-groups validity, scores difference between depressed and non-depressed patients were 
compared using Mann-Whitney Test. $P<0.05$ means statistical significance.

\section{Results}

\section{Demographic and clinical characteristics}

A total of 201 patients participated in this study at their first visit, and $98 \%$ of them were women. The mean (SD) age was 38.5(10.9) years, and median disease duration was 6 years. The median SLEDAI score was 4 . Other variables were showed in Table 1. 184 patients completed the second investigation of fatigue on the phone.

\section{Acceptability and dimensionality}

For floor and ceiling effects, $4.5 \%$ of the sample had the lowest possible score and $4 \%$ of them got the highest possible score. The Kaiser-Meyer-Olkin (KMO) value was 0.92 , indicating the sample size was suitable for factor analysis. With the use of principal factors method and quartimax rotation, one factor was revealed, and scree plot also justified this result. One factor explained $61.80 \%$ of the total variance. Factor loadings ranged from 0.59 to 0.86 (Table 2). Item 1 and item 2 showed the lowest correlation with the rest of the items (Table 3). When we deleted item 1 and item 2, one factor was extracted, and 7 items explained $69.54 \%$ of the total variance. Factor loadings ranged from 0.67 to 0.88 (Table 2).

\section{Reliability and validity}

Cronbach's Alpha showed a minor increase from 0.92 to 0.93 when item 1 and item 2 were deleted. ICC was 0.94 , and there was no significant change in ICC after the deletion of items. We found significant correlation between 9-item FSS score and SDS score $(r=0.52, P<0.01)$. Significant correlation between 9-item FSS score and Vitality score $(r=-0.55, P<0.01)$ was also found (Table 4$)$. The correlation coefficient between 7-item FSS score and Vitality score increased $(r=-0.58, P<0.01)$, while the correlation coefficient between 7-item FSS score and depression score remained the same (Table 4). Mann-Whitney Test showed that patients with depression demonstrated higher median fatigue score both for 9-item FSS and 7 -item FSS $(P<0.001)$ (Table 5).

\section{Discussion}

FSS has been translated into Chinese version but hasn't been applied in SLE patients. As fatigue is one of the mostly referred subjective symptoms in SLE, there is a need for a reliable instrument to assess this problem. This was the first study to test the psychometric properties of FSS in Chinese SLE patients. Our study showed that original 9-item FSS had acceptable psychometric properties, in accordance with findings from other language versions in different populations [28, 33, 34]. And
Table 1 Demographic and Clinical Characteristics of SLE patients

\begin{tabular}{|c|c|}
\hline Variable & Value \\
\hline Age, mean (SD) & $38.5(10.9)$ \\
\hline \multicolumn{2}{|l|}{ Gender, $n(\%)$} \\
\hline Female & $197(98.0)$ \\
\hline Male & $4(2.0)$ \\
\hline \multicolumn{2}{|l|}{ Level of education, $n(\%)$} \\
\hline Illiterate & $15(7.5)$ \\
\hline Elementary and junior high school & 79(39.3) \\
\hline High school/vocational high school & $83(41.3)$ \\
\hline University and college & 20(9.9) \\
\hline Graduate school & $4(2.0)$ \\
\hline \multicolumn{2}{|l|}{ Residence, $n$ (\%) } \\
\hline Rural area & $91(45.3)$ \\
\hline Urban area & $110(54.7)$ \\
\hline \multicolumn{2}{|l|}{ Current work status, $n$ (\%) } \\
\hline Retired & $5(2.5)$ \\
\hline Unemployed & $82(40.8)$ \\
\hline Employed & 114(56.7) \\
\hline \multicolumn{2}{|l|}{ Average monthly household income, $n$ (\%) } \\
\hline 0 2000 RMB & $92(45.8)$ \\
\hline $2000 \sim 5000 \mathrm{RMB}$ & $89(44.3)$ \\
\hline $5000 \sim 10,000 \mathrm{RMB}$ & $12(6.0)$ \\
\hline$\geq 10,000 \mathrm{RMB}$ & $8(3.9)$ \\
\hline \multicolumn{2}{|l|}{ Medical insurance, $n(\%)$} \\
\hline Yes & $99(49.3)$ \\
\hline No & $102(50.7)$ \\
\hline \multicolumn{2}{|l|}{ Whether having caregiver, $n(\%)$} \\
\hline Yes & 169(84.1) \\
\hline No & $32(15.9)$ \\
\hline Disease duration, median (range), years & $6(0.08,38)$ \\
\hline SLADAI score, median (range) & $4(2,45)$ \\
\hline \multicolumn{2}{|l|}{ Daily glucocorticoids dose, $n$ (\%) } \\
\hline$\leq 7.5 \mathrm{mg}$ & $77(38.3)$ \\
\hline $7.5 \sim 30 \mathrm{mg}$ & $118(58.7)$ \\
\hline $30 \sim 100 \mathrm{mg}$ & $6(3)$ \\
\hline \multicolumn{2}{|l|}{ Depression, $n(\%)$} \\
\hline No & $112(55.7)$ \\
\hline Mild & $53(26.4)$ \\
\hline Moderate & $31(15.4)$ \\
\hline high & $5(2.5)$ \\
\hline
\end{tabular}

the 7-item FSS also have good psychometric properties for Chinese SLE patients.

When more than $15 \%$ of the samples have either the lowest or the highest score, the instrument demonstrates 
Table 2 Factor analysis for the 9-item FSS and 7-item FSS

\begin{tabular}{lll}
\hline Item & $\begin{array}{l}\text { Factor } \\
\text { loading }\end{array}$ & $\begin{array}{l}\text { Factor } \\
\text { loading }\end{array}$ \\
\hline $\begin{array}{l}\text { Item1 (My motivation is lower when } \\
\text { I am fatigued) }\end{array}$ & 0.59 & - \\
Item2(Exercise brings on my fatigue) & 0.67 & - \\
Item3 (I am easily fatigued) & 0.70 & 0.67 \\
Item4 (Fatigue interferes with my & 0.86 & 0.86 \\
physical functioning) & & \\
Item5 (Fatigue causes frequent \\
problems for me) \\
$\begin{array}{l}\text { Item6 (My fatigue prevents sustained } \\
\text { physical functioning) }\end{array}$ & 0.86 & 0.88 \\
Item7 (Fatigue interferes with carrying & 0.86 & 0.87 \\
out certain duties and responsibilities) & & 0.85 \\
Item8 (Fatigue is among my three most \\
disabling symptoms)
\end{tabular}

Note: KMO Kaiser-Meyer-Olkin value

floor and ceiling effects [35]. In our study, $4.5 \%$ of the samples had the lowest score and $4 \%$ had the highest score, indicating the ceiling and floor effects were minimal. However, Ferentinos' study [36] demonstrated a ceiling effect of FSS in major depression subjects. Possible explanation may be that depressed patients are more sensitive to negative feelings and experiences so they are more likely to choose higher score of FSS. Such result indicated that the acceptability of the FSS differs in different patient group, which further confirmed the importance to test the psychometric properties of an instrument before applying it to a specific disease.

Exploratory factor analysis results were in agreement with previous studies using FSS in SLE patients [27-29]. Only one factor was extracted in our sample, explaining $61.80 \%$ of the total variance. All the item loadings were

Table 3 Item-total correlation for the 9-item FSS and 7-item FSS

\begin{tabular}{lll}
\hline Item & Total 9-item FSS score & Total 7-item score \\
\hline Item 1 & 0.52 & - \\
Item 2 & 0.59 & - \\
Item 3 & 0.62 & 0.58 \\
Item 4 & 0.80 & 0.80 \\
Item 5 & 0.80 & 0.82 \\
Item 6 & 0.81 & 0.81 \\
Item 7 & 0.78 & 0.80 \\
Item 8 & 0.79 & 0.80 \\
Item 9 & 0.73 & 0.75 \\
\hline
\end{tabular}

Table 4 Correlation of the FSS score with depression and vitality score

\begin{tabular}{lll}
\hline Variable & FSS-9 & FSS-7 \\
\hline Depression & $0.52^{* *}$ & $0.52^{* *}$ \\
Vitality & $-0.55^{* *}$ & $-0.58^{* *}$ \\
\hline Note: ${ }^{* *}=P<0.01$ & &
\end{tabular}

higher than 0.40. The first and second item showed the lowest correlation with the rest of the items, in line with Lerdal's report [26]. Ottonello's study [37] reported that deletion of item 1 could improve the unidimensionality of the FSS in Italian MS patients. Lerdal's study concluded that the removal of item 1 and item 2 could improve FSS's psychometric properties in MS and stroke patients [14, 38], while Mill's study [39] concluded that a 5-item FSS scale could measure the impact of the fatigue better than the original 9-item scale in MS patients. Wang's study indicated that the deletion of item 2 and item 3 showed better psychometric properties in major depressive disorder participants [23]. When we deleted item 1 and item 2, 7 items explained $69.54 \%$ of the total variance.

Past studies demonstrated that the Cronbach's Alpha of FSS ranged from 0.87 to 0.96 [34, 40-43] in different language versions and different disease subgroups. The original FSS had good internal consistency. Our study found that the Cronbach's Alpha showed a minor increase from 0.92 to 0.93 after the deletion of item 1 and item 2. Possible reason may be that the description of item 1 and item 2 can't measure the severity of fatigue, and they lack the discrimination ability for healthy and disease-suffered groups since healthy people can also have such experiences. The test-retest reliability was good, indicating that it was a stable instrument to use at different interval.

The original FSS showed acceptable construct validity. Significant correlation between FSS score and depression score $(r=0.52, P<0.01)$ was found, in line with past studies showing that the correlation coefficient ranged from 0.46 to 0.75 [40, 44, 45]. What's more, correlation was also found between FSS score and score of Vitality $(r=-0.55$, $P<0.01)$, in accordance with previous reports, in which the correlation coefficient ranged from -0.32 to -0.72

Table 5 Comparison of fatigue in patients with or without depression

\begin{tabular}{|c|c|c|c|c|}
\hline & \multicolumn{2}{|l|}{ 9-item FSS } & \multicolumn{2}{|l|}{ 7-item FSS } \\
\hline & $\begin{array}{l}\text { With } \\
\text { depression } \\
(n=89)\end{array}$ & $\begin{array}{l}\text { Without } \\
\text { depression } \\
(n=112)\end{array}$ & $\begin{array}{l}\text { With } \\
\text { depression } \\
(n=89)\end{array}$ & $\begin{array}{l}\text { Without } \\
\text { depression } \\
(n=112)\end{array}$ \\
\hline Median & 4.80 & 3.35 & 4.43 & 2.57 \\
\hline z & & -5.56 & & -5.70 \\
\hline$P$ value & & $0.000^{\mathrm{a}}$ & & $0.000^{\mathrm{a}}$ \\
\hline
\end{tabular}

Note: SDS score $\geq 50$ means depression, and SDS score $<50$ means no depression

${ }^{\mathrm{a}}$ Mann-Whitney test 
[27, 34, 46]. After the deletion of the item 1 and 2, the concurrent validity seemed better since the correlation coefficient between 7-item FSS score and Vitality score increased $(r=-0.58, \quad P<0.01)$, while the correlation coefficient between 7-item FSS score and depression score remained the same $(r=0.52, P<0.01)$ (Table 4$)$.

Known-groups validity was tested by comparing fatigue difference between patients with and without depression. We hypothesized that patients with depression would show higher degree of fatigue. And our result verified such hypothesis, showing FSS's suitable ability to reflect differences between two groups both for original FSS and 7-item FSS (Table 5).

Our study did have some limitations. Firstly, we only investigated SLE patients in one general hospital with a small number of male patients, and the female to male ratio was less than the reported ratio in Chinese SLE patients, so the representativeness of the samples may be reduced. Secondly, the overall disease activity of SLE was mild, so further investigation of SLE with different level of disease activity are necessary to increase study's generalizability. Finally, depression can have some impacts on the fatigue problem of SLE patients. Our study didn't exclude the depressive patients as depression and fatigue can be interactive in SLE patients and it may be impractical to distinguish these two symptoms in SLE patients.

\section{Conclusion}

In summary, 9-item FSS is a reliable instrument and can be used to assess fatigue problem in Chinese SLE. The 7-item FSS also demonstrated good psychometric properties. As the deletion of two items simplify the content of FSS, it may make patients more willing to participate in study. However, another study about whether the 7-item FSS is more easy to use from patients' perspectives is needed.

\section{Abbreviations}

FSS: Fatigue severity scale; ICC: Intraclass correlation coefficient; SD: Standard deviation; SDS: Self-Rating depression scale; SLE: Systemic lupus erythematosus; SLEDAI: Systemic lupus erythematosus disease activity index

\section{Acknowledgments}

Not applicable.

\section{Funding}

This study was supported by the China Medical Board (0082827601130) and the Science and Technology Department of Sichuan Province (2013FZ0088).

\section{Availability of data and materials}

The dataset of our study is not publicly available due to it containing information that could compromise participants' privacy but is available from the corresponding author with acceptable reasons.

\section{Authors' contributions}

$\mathrm{CCF}, \mathrm{QH}$, and SZZ were responsible for the design of the study. YW, XKH and JW were responsible for data analysis and interpretation. CCF drafted the article. $\mathrm{XLH}$ assisted in writing. All authors read and approved the final manuscript.
Consent for publication

Not applicable.

\section{Competing interests}

The authors declare that they have no competing interests.

\section{Publisher's Note}

Springer Nature remains neutral with regard to jurisdictional claims in published maps and institutional affiliations.

Received: 17 April 2018 Accepted: 10 April 2019

Published online: 24 April 2019

\section{References}

1. Askanase A, Shum K, Mitnick H. Systemic lupus erythematosus: an overview. Soc Work Health Care. 2012;51:576-86.

2. Mok CC. Epidemiology and survival of systemic lupus erythematosus in Hong Kong Chinese. Lupus. 2011;20:767-71.

3. Yeh KW, Yu CH, Chan PC, Horng JT, Huang JL. Burden of systemic lupus erythematosus in Taiwan: a population-based survey. Rheumatol Int. 2013; 33:1805-11.

4. Ponsestel GJ, Alarcón GS, Scofield L, Reinlib L, Cooper GS. Understanding the epidemiology and progression of systemic lupus erythematosus. Semin Arthritis Rheum. 2010;39:257-68.

5. Wang Z, Wang Y, Zhu R, Tian X, Xu D, Wang Q, et al. Long-term survival and death causes of systemic lupus erythematosus in China: a systemic review of observational studies. Medicine. 2015. https://doi.org/10.1097/md. 0000000000000794.

6. Feng $X$, Pan W, Liu L, Wu M, Ding F, Hu H, et al. Prognosis for hospitalized patients with systemic lupus erythematosus in China: 5-year update of the Jiangsu cohort. PLoS One. 2016. https://doi.org/10.1371/journal.pone. 0168619.

7. Li W, Ye Z, Yin Z, Zhang K. Clinical and immunological characteristics in 552 systemic lupus erythematosus patients in a southern province of China. Int J Rheum Dis. 2017. https://doi.org/10.1111/1756-185X.12480.

8. Zhang S, Su J, Li X, Zhang X, Liu S, Wu L, et al. Chinese SLE treatment and research group (CSTAR) registry: $V$. gender impact on Chinese patients with systemic lupus erythematosus. Lupus. 2015;24:1267-75.

9. Cleanthous S, Tyagi M, Isenberg DA, Newman SP. What do we know about self-reported fatigue in systemic lupus erythematosus? Lupus. 2012;21:465-76.

10. Ozel F, Argon G. The effects of fatigue and pain on daily life activities in systemic lupus erythematosus. Agri. 2015;27:181-9.

11. Sterling K, Gallop K, Swinburn P, Flood E, French A, Al Sawah S, et al. Patient-reported fatigue and its impact on patients with systemic lupus erythematosus. Lupus. 2014;23:124-32.

12. Palagini L, Tani C, Mauri M, Carli L, Vagnani S, Bombardieri S, et al. Sleep disorders and systemic lupus erythematosus. Lupus. 2014:23:115-23.

13. Ad Hoc Committee on Systemic Lupus Erythematosus Response Criteria for Fatigue. Measurement of fatigue in systemic lupus erythematosus: a systematic review. Arthritis Rheum. 2007;57:1348-57.

14. Lerdal A, Kottorp A. Psychometric properties of the fatigue severity scaleRasch analyses of individual responses in a Norwegian stroke cohort. Int J Nurs Stud. 2011;48:1258-65.

15. Belza BL, Henke CJ, Yelin EH, Epstein WV, Gilliss CL. Correlates of fatigue in older adults with rheumatoid arthritis. Nurs Res. 1993;42:93-9.

16. Krupp LB, LaRocca NG, Muir-Nash J, Steinberg AD. The fatigue severity scale. Application to patients with multiple sclerosis and systemic lupus erythematosus. Arch Neurol. 1989:46:1121-3.

17. Chalder T, Berelowitz G, Pawlikowska T, Watts L, Wessely S, Wright D, et al. Development of a fatigue scale. J Psychosom Res. 1993;37:147-53.

18. Smets EM, Garssen B, Bonke B, De Haes JC. The multidimensional fatigue inventory (MFI) psychometric qualities of an instrument to assess fatigue. J Psychosom Res. 1995;39:315-25.

19. Stone P, Richards M, A'Hern R, Hardy J. A study to investigate the prevalence, severity and correlates of fatigue among patients with cancer in comparison with a control group of volunteers without cancer. Ann Oncol. 2000;11:561-7.

20. Rosa K, Fu M, Gilles L, Cerri K, Peeters M, Bubb J, et al. Validation of the fatique severity scale in chronic hepatitis C. Health Qual Life Outcomes. 2014;12:1-12. 
21. Yan S, Wu Y, Deng Y, Liu Y, Zhao J, Ma L. Risk factors for fatigue in patients with epilepsy. J Clin Neurosci. 2016;33:134-7.

22. Takasaki H, Treleaven J. Construct validity and test-retest reliability of the fatigue severity scale in people with chronic neck pain. Arch Phys Med Rehabil. 2013;94:1328-34

23. Wang MY, Liu IC, Chiu CH, Tsai PS. Cultural adaptation and validation of the Chinese version of the fatigue severity scale in patients with major depressive disorder and nondepressive people. Qual Life Res. 2016;25:89-99.

24. Tang WK, Lu JY, Chen YK, Mok VC, Ungvari GS, Wong KS. Is fatigue associated with short-term health-related quality of life in stroke? Arch Phys Med Rehabil. 2010;91:1511-5.

25. Chen YK, Qu JF, Xiao WM, Li WY, Weng HY, Li W, et al. Poststroke fatigue: risk factors and its effect on functional status and health-related quality of life. Int J Stroke. 2015;10:506-12.

26. Lerdal A, Wahl A, Rustoen T, Hanestad BR, Moum T. Fatigue in the general population: a translation and test of the psychometric properties of the Norwegian version of the fatigue severity scale. Scand J Public Health. 2005; 33:123-30.

27. Mattsson M, Moller B, Lundberg I, Gard G, Bostrom C. Reliability and validity of the fatigue severity scale in Swedish for patients with systemic lupus erythematosus. Scand J Rheumatol. 2008:37:269-77.

28. Alsobayel HI, Alhugail HA, Alsaif RM, Albawardi NM, Alnahdi AH, Daif AM, et al. Validation of an Arabic version of fatigue severity scale. Saudi Med J. 2016:37(1):73-8

29. Lorentzen K, Danielsen MA, Kay SD, Voss A. Validation of the fatigue severity scale in Danish patients with systemic lupus erythematosus. Dan Med J. 2014;61(4):A4808.

30. Hochberg MC. Updating the American College of Rheumatology revised criteria for the classification of systemic lupus erythematosus. Arthritis Rheum. 1997. https://doi.org/10.1002/1529-0131(199709)40:93. $0 . \mathrm{CO} ; 2-\mathrm{Y}$.

31. Valko PO, Bassetti CL, Bloch KE, Held U, Baumann CR. Validation of the fatigue severity scale in a Swiss cohort. Sleep. 2008;31:1601-7.

32. Shen B, Tan W, Feng G, He Y, Liu J, Chen W, et al. The correlations of disease activity, socioeconomic status, quality of life, and depression/anxiety in Chinese patients with systemic lupus erythematosus. Clin Dev Immunol. 2016. https://doi.org/10.1155/2013/270878.

33. Rosti-Otajarvi E, Hamalainen P, Wiksten A, Hakkarainen T, Ruutiainen J. Validity and reliability of the fatigue severity scale in Finnish multiple sclerosis patients. Brain behave. 2017;7:e00743.

34. Nadarajah M, Mazlan M, Abdul-Latif L, Goh HT. Test-retest reliability, internal consistency and concurrent validity of fatigue severity scale in measuring post-stroke fatigue. Eur J Phys Rehabil Med. 2016;53:703-9.

35. Terwee CB, Bot SD, de Boer MR, van der Windt DA, Knol DL, Dekker J, et al. Quality criteria were proposed for measurement properties of health status questionnaires. J Clin Epidemiol. 2007;60:34-42.

36. Ferentinos P, Kontaxakis V, Havaki-Kontaxaki B, Dikeos D, Lykouras L. Psychometric evaluation of the fatigue severity scale in patients with major depression. Qual Life Res. 2011:20:457-65.

37. Ottonello M, Pellicciari L, Giordano A, Foti C. Rasch analysis of the fatigue severity scale in Italian subjects with multiple sclerosis. J Rehabil Med. 2016; 48:597-603.

38. Lerdal A, Johansson S, Kottorp A, von Koch L. Psychometric properties of the fatigue severity scale: Rasch analyses of responses in a Norwegian and a Swedish MS cohort. Mult Scler. 2010;16:733-41.

39. Mills R, Young C, Nicholas R, Pallant J, Tennant A. Rasch analysis of the fatique severity scale in multiple sclerosis. Mult Scler. 2009;15:81-7.

40. Laranjeira CA. Translation and adaptation of the fatigue severity scale for use in Portugal. Appl Nurs Res. 2012;25:212-7.

41. Fereshtehnejad SM, Hadizadeh H, Farhadi F, Shahidi GA, Delbari A, Lokk J. Reliability and validity of the persian version of the fatique severity scale in idiopathic Parkinson's disease patients. Parkinsons Dis. 2013. https://doi.org/ 10.1155/2013/935429.

42. Burger $\mathrm{H}$, Franchignoni F, Puzic N, Giordano A. Psychometric properties of the fatigue severity scale in polio survivors. Int J Rehabil Res. 2010;33:290-7.

43. Impellizzeri FM, Agosti F, De Col A, Sartorio A. Psychometric properties of the fatigue severity scale in obese patients. Health Qual Life Outcomes. 2013. https://doi.org/10.1186/1477-7525-11-32

44. Valderramas S, Feres AC, Melo A. Reliability and validity study of a BrazilianPortuguese version of the fatigue severity scale in Parkinson's disease patients. Arq Neuropsiquiatr. 2012;70:497-500.
45. Learmonth YC, Dlugonski D, Pilutti LA, Sandroff BM, Klaren R, Motl RW. Psychometric properties of the fatigue severity scale and the modified fatigue impact scale. J Neurol Sci. 2013;331:102-7.

46. Bakalidou D, Skordilis EK, Giannopoulos S, Stamboulis E, Voumvourakis K. Validity and reliability of the FSS in Greek MS patients. SpringerPlus. 2013. https://doi.org/10.1186/2193-1801-2-304.
Ready to submit your research? Choose BMC and benefit from:

- fast, convenient online submission

- thorough peer review by experienced researchers in your field

- rapid publication on acceptance

- support for research data, including large and complex data types

- gold Open Access which fosters wider collaboration and increased citations

- maximum visibility for your research: over $100 \mathrm{M}$ website views per year

At BMC, research is always in progress.

Learn more biomedcentral.com/submissions 